\title{
Digital media environment is analysed in print ads creative teaching
}

\section{innovation}

\section{Xiaowen Zhang}

\section{Qingdao Agricultural University,266109}

\section{Keywords: digital media teaching reform plane advertisement design}

\begin{abstract}
The rapid development of digital media to plane advertisement design talent cultivation put forward the new requirements, print advertising design education must be timely adjust teaching ideas, curriculum design innovation.The author first analyzes the digital media talent demand changes, under the background of print ads should resume is presented in this era of digital media plane advertisement design teaching system, and probes into the reform of the teaching contents and
\end{abstract} forms of plane advertisement design of the new plan.

Rapid progress in the development of digital media, species and quantity increasing. Yin yungong, editor at the Chinese academy of social sciences of the China digital media development report (2012) pointed out that our country has the world's most extensive digital media user base and one of the most abundant digital media application.Digital collection of radio, television, print media, network, electronic publishing, mobile communications and other information medium into an organic whole, on video, text, images, data and other comprehensive treatment, provide consumers with comprehensive, diversified information service, makes the plane advertisement publishing platform, release way, communication strategy and so on are the effective and continuous extension, make print advertising visual communication become diversified and more influential.According to the forecast carat media, digital print ads in 2014 of the world's share of print advertising spending will rise to $20 \%$. As the Internet, mobile phones, digital TV digital media such as print ads, all kinds of new media plane advertisement increasing demand, traditional forms of print ads and making means constantly replaced by digital media and new technologies, static graphic print ads increasingly being dynamic, the challenges of the new media print ads, demand also quietly changed, then the plane advertisement design talent cultivation put forward higher requirements.Digital media era in print advertising design and production is not just a technical level, it requires that the creator has the comprehensive science and the humanities accomplishment, improve the reasonable knowledge structure, a new way of cognition and judgment of plane advertisement design talented person's raise more in need of new thinking, new ideas, new methods.Plane advertisement design is visual communication design and plane advertising communication specialized core curriculum, it to printing, communication, network, video, and other forms as the carrier, research at home and abroad the latest plane advertisement design art form, is an innovative form of course.However, most existing print advertising design is still in the traditional plane advertisement design processes in the teaching design, media such as newspapers, magazines, radio, television and other plane advertisement design content, the various forms of digital media print ads, new features and design methods in plane advertisement design course more just mentioned without specification as the teaching content, make it hard for students to quickly master the law of digital media plane advertisement design and the method.Media form the rapid changes gave us many new problems and new tasks, the plane advertisement design teaching model 
has not completely adapt to new requirements, knowledge structure, teaching focus is qualitative change, the teaching ideas of the plane advertisement design should conform to the requirements in the digital media era.The author according to the characteristics of digital media, from the analysis of plane advertisement design and the relationship of digital media, the digital media era of plane advertisement design teaching content, and experience in traditional teaching pattern and teaching mode on the basis of the proposed increase practice teaching link in with the new media as the core, focusing on the cultivation of specialized personnel mastering many skills while specializing in one type of plane advertisement design, the foundations of the digital media era of plane advertisement design teaching system.Specific include the following three aspects:

\section{To adapt to the characteristics of digital media interactive teaching}

Digital media has spread the quantitative and personalized interaction, communication channel etc.At the same time, digital media is represented by the Internet, most college students contact the longest media contact time.

In the network, mobile phones, tablets and other emerging carrier of information dissemination environment of student community is an important part of digital media audience, their visual representation of the digital media plane advertisement design, interactive experience, and expected effect feeling directly, to some extent, even more than the teacher.

Therefore, in the plane advertisement design curriculum, teachers need to adapt to the characteristics of digital media, take advantage of the spread of digital media, into more teaching interaction to enrich and improve the course content and improve teaching effect.

Research data show that in the United States, $90 \%$ of the teachers to use social media to cooperate in class teaching, $20 \%$ of the teachers encourage students to communicate through the digital media platform. Can adapt to the characteristics of digital media interactive teaching from the following three aspects: first, change passive to active, enhance creativity. Through students' collecting information and independent research to break the bondage of the teaching material, on the basis of the basic theory study, arouse the enthusiasm of students, this paper summarizes let students based on their own practice, and fully understand the advantages and characteristics of digital media era plane advertisement teaching and design methods.Such as, the teacher can according to the teaching content of each chapter, prior arrangement with a learning task, let the students free search knowledge and related network audio and video content, and then specify the students read some classic or representative material to deepen understanding.In teaching teachers encourage students to use digital media practice learning outcomes, such as according to the class of material character design for oneself to like a facebook page or article Banner plane advertisement design, etc.Second, the interaction of teachers and students. Cell phones, weibo, renren has become college students contact the main way to communicate, receive messages, we have learned, now most of the students are well hook or weibo account, can through the mobile Internet.

Digital media as students to acquire knowledge and information, entertainment, dating an important platform and channel, also accelerated the change of the role of teachers, make it a practice situation of designers, excitation of problem consciousness, practice the chief director of the project.Teachers can through digital media close to the needs of students, and students to interact and become students after-school learning bloggers, online friends, mutual when fans, etc.In addition, with the development of digital media technology, the multimedia network classroom, design teaching can achieve group speech class discussion, homework to revise; Teachers and students both sides instant dialogue through a computer can be one-on-one, discusses research; Application of database system, all the teaching content can be stored and calls, teaching 
information to share with students more easily.

\section{Around digital media content of plane advertisement design course}

Digital media has huge amounts of sexual characteristics and the content of the multimedia and hypertext and sharing, and made the change in plane advertisement design teaching content become inevitable, past a single paper teaching material content is no longer the center of the whole teaching activity.Therefore, in teaching content, teachers need to follow the industry development of teaching content adjustment, improve and expand the traditional knowledge system, the static knowledge system and the digital teaching resources and an organic combination of information technology platform, the outlook of students.

Add digital media plane advertisement design content is the radiation center of the information. First of all, on the curriculum content arrangement, the teacher can not limited the scope of the traditional media should pay more attention to digital media courses, increasing network plane advertisement design, implantable advertising design, outdoor print $\mathrm{AD}$ design, etc.Increase in the chapter of social media (such as weibo, WeChat), mobile digital media (such as mobile phones, tablet client) latest media form transmission form, characteristics and strategies of chapters and visual forms of digital media print ads related cases.For example, to add detail to the classroom plane advertisement design case, verification code embedded graphic advertising design case, case LED screen print ads, etc.Secondly, in the design skills training, the teacher should pay attention to training students' practical ability of new media technology, make its master all kinds of new media plane advertisement design skills, understand the material composition of all kinds of new media, to enable students to know environment in different print ads use different material of new media technology, such as the selection of the large outdoor LED display material.Moreover, integrated digital media in plane advertisement design practices, teachers can guide students to take advantage of digital media design material collection, such as graphics, text, audio, video, animation, tables, etc., to establish students' personal repository, at the same time, the different digital media such as network information resources, mobile phones, outdoor video collection, refining and processing, electronic newspapers, etc, finally realizes the digital media design material and digital media, the integration of information resources sharing, integration of existing resources to plane advertisement design creation.

\section{Increase in the practice teaching link of new media as the core}

Plane advertisement design is a practical subject and the more practical teaching link in with the new media as the core, can let the student to absorb the latest digital media in practice social demand information, practice the classroom knowledge already, can spontaneously contact with society, so as to promote the academic update and improve the quality of our education.

First, encourage students to participate in plane advertisement design competition. Along with the development of digital media, plane advertisement design competition sponsored by the department of education departments such as sponsored by ministry of education "national college students print advertising art competition", related organizations hosted competitions such as "jingdu awards", sponsored by the China print advertising association "academy" and so on, are set up and digital media related events, such as network micro film, print ads, network video, weibo popular works, such as publicity work submitted and also on the website, the cooperation media, social media.The contest is a important bridge between academia and industry, has a certain frontier and authoritative and practical, to participate in these events will help comprehensive inspection 
knowledge level and the comprehensive quality of students.In the teaching of plane advertisement design, teachers and students should attaches great importance to the use of new media, strengthen the cultivation of digital media plane advertisement design ability, teachers should consciously events for students print ads as talent training mode reform and exploration, an important part of exercise for students active integrate social channels, inspire students' innovative thinking and practice, let the student fully practice a variety of media way of plane advertisement design creation process.

Second, import the real subject, has well for students to create more social practice of the related digital media plane advertisement design opportunities and conditions.Such as, through the visit, market research, scientific research cooperation, and practice investigation, employment training and so on the many kinds of organization form, let the students fully participate in the network plane advertisement company or other digital media advertising company's daily activities, familiar with digital media from different levels, different angles of plane advertisement design, business and management master engaged in digital media art, print AD design, and related work ability.

At the same time, also can cooperate with campus service institutions and relevant enterprises, appropriate to carry out the new media business, such as the construction of the campus website, weibo platform maintenance, the high quality course website construction, network between colleges plane advertisement design, campus outdoor LED display plane advertisement design, etc., make it become a new medium exercise students practical ability.

The rapid development of digital media greatly affected the plane advertisement design teaching content and teaching form, to cultivate students' innovative thinking and practical ability put forward new requirements.In the face of digital media on the impact of plane advertisement design teaching mode, teachers need to be able to further understand the characteristics of the digital media era of information dissemination, to grasp the digital media plane advertisement advantage, on the basis of the traditional teaching contents and teaching mode innovation, strengthen the practice teaching of digital media print ads, cultivate the students' practical ability, fully stimulate students' interest in the design and exploration enthusiasm, for students to better adapt to the emerging media communication in the future technical requirements. Only think deeply about the characteristics of the digital media era plane advertisement design, summarizes the advantages and disadvantages of plane advertisement design, under the current environment, actively explore, bold innovation, to further improve the digital media era of plane advertisement design teaching system, the training of specialists in the field of meet the requirements of the era of digital media design.

Note: the article is huazhong agricultural university, the key course construction project research results to plane advertisement design。

\section{References:}

[1] Xu Qiaohui.Shallow of art education curriculum innovation in digital media environment. Decoration, 2010 (6).

[2]CuiLei, ShuYongping...Under the new media environment plane advertising professional practice ability training goal and way. Print ads observatory (theory), 2010 （5）.

[3]Ma Zhaofeng..Print advertising performance change theory of digital media era. The press, 2009 (5). 